\title{
Gender Disparity in English Language Textbooks in Nigeria: Bridging the Gap for Literacy Development
}

\author{
Iduma Ogbonnaya-Iduma Angela
}

Ebonyi State University, Abakaliki-Nigeria

\section{Doi:10.5901/jesr.2014.v4n7p19}

\begin{abstract}
The study investigates gender disparity in English Language textbooks. Four major English Language texts are selected and each of them runs into six series giving a total of twenty four books used for the study. Content analysis is used as it helps to determine the gender that is under-represented or overrepresented in the books. The content in this study is divided into the activities assigned to males and females: Characterization, leisure activities, professional/occupational stereotypes, domestic activities and undesirable qualities ascribed to males and females. The general findings indicate disparity against both males and females although females are largely discriminated against in the areas of domination in characterization, undesirable qualities, representation, invisibility, occupational/professional and domestic stereotypes. This discrimination would affect the reading psychology of the students and subsequently not permit meaningful literacy development especially among the females. Based on the findings, it is recommended, above all that there should be orientation/sensitization training and workshops frequently organized for students, teachers/teacher trainers, authors and publishers on gender issues and, gender education courses should be introduced in our institutions of higher learning. There should be policies/guidelines made by the government to guarantee gender balance in authorship/publication of textbooks and the implementation monitored.
\end{abstract}

Keywords: Gender, English Textbooks, Literacy Development

\section{Introduction}

No meaningful development can be achieved in any nation that has low literacy level. This makes the Nigerian government to embark on mass literacy by the introduction of free education especially in the basic levels of education (as well as in the post primary levels, by some state governments). The federal government equally launched the Universal Basic Education (UBE), National Training Institute (NTI), Volunteer Service Scheme (VSS) and Subsidy Reinvestment Programme (SURE-P), to wage war against illiteracy. In these institutions, teachers are trained and dispatched to schools to combat illiteracy.

The major step to fighting illiteracy is by the teaching and learning of reading and writing. The trained teachers are expected to help the pupils/students in the schools they are posted to achieve this. Other professional teachers are to lead in the task of teaching children to read, write and advance in literacy. Achieving this depends on many factors among which are the type, language and content of the texts used by the students. Many of the textbooks used in the schools have been shown to reflect gender discrimination (Mustapha 2012) thereby placing a limitation to literacy development in Nigeria.

Moreover, reading is a means of accessing the information contained in any text, thus the importance of reading especially to students, cannot be over-emphasized. Reading helps in the building of one's' world knowledge, sharpen reasoning, spark off imaginations and equip an individual for a life-long learning. Reading is a channel for learning people's culture, religion and beliefs. The cultural beliefs of some writers have a way of affecting what they write which consequently affect the readers. This is the case with the English language textbooks especially, some of the English language prescribed texts which in diverse areas unduly promote gender disparity.

In addition, the African society, especially Nigeria, is replete with gender stereotyping. According to Martin and Halverson (1981), gender stereotypes indicate "subjective perception of what a man or woman should be or how people should behave". Equally, fung and Ma (2000) indicate that stereotype is a subjective perception that may be an intuition, a prejudice, an imagination, or past impression of what a person has been. In the Nigerian society, men are stereotyped as the strong, brave and intelligent lords. They are presented as the ones to handle tough and strong issues as well as those who have monopoly of knowledge and leadership. They are portrayed as the infallible lords of the manor at whose command the woman should obey without questioning. On the other hand, the females are revealed as the weak ones 
who are perpetually dependent on the males for everything. They are stereotyped as the ones that are only capable of producing children and keeping the homes. According to Oyebola (2004), these stereotyping are gradually permeating into the school system. This is evident in the English language textbooks of secondary school students.

UNESCO(1998) shows the following as effects of gender stereotyping

1. Impression management: women and men start behaving the way stereotypes portray their respective sexes.

2. Negative self-fulfilling prophesy, example, if a school perceive females as not as good in Mathematics and science as males, the females may accept this false notion and stop working hard on these subjects.

3. Negative self confidence and self control.

This accounts for the need for this study to investigate gender discrimination in English language textbooks using the following texts: Intensive English (2010 edition) published by Africana First publishers Limited, New Concept English (2013 edition) published by Learn Africa PLC, New Oxford English (2008 edition) and English Project for Secondary Schools (Junior and Senior). These books are in series of Junior Secondary and Senior Secondary Schools one to three and they are used in this study for the investigation.

\section{Statement of the Problems}

Despite the loud cries globally against gender discrimination and illiteracy, it is obvious that gender bias is still displayed both in the Nigerian society and in the school system, thereby hindering literacy development. Books which are expected to be tools for arresting this problem are rather means of strengthening it. Researches indicate that many textbooks used by students are full of unequal representation of the roles of males and females (Mustapha 2012). The fact that children are influenced by the pictures in their textbooks and what they read from it show that gender stereotyping would be encouraged if the roles assigned to both males and females are not equitably distributed in the texts they read. It is as a result of this that this study is carried out to investigate gender disparity in the English language textbooks used by Secondary School students in Nigeria and proffer solutions that would account for literacy development.

\section{Purpose of the Study}

The purpose of the study is to investigate gender disparity displayed in English language texts in Nigeria and proffer solutions that would encourage literacy development.

\section{Methodology}

Four different types of English language textbooks for secondary schools in Nigeria which are commonly used are selected for the study. Each of the books is in series of Junior Secondary School (JSS) one to three and Senior Secondary School (SSS) one to three and they include: Intensive English by Africana First Publishers Plc, New Concept English by Felix Iwerebon House, New Oxford English and English Project for Secondary Schools (Junior and senior) by University Press Plc. The four textbooks which run into six series each, amount to twenty four books used in the study. The names of the publishers are used to represent the books instead of their authors because the books are easily identified by their publishers. This is due to, perhaps that publishers make demands for the writing of the books and they are the ones that convince the government to prescribe their books for use in schools. More so, the choice of these books is made because they are highly recommended by government owned and private schools.

In this type of study, Opeke (2002) shows that many methods can be used. They are; quantitative analysis of content, analysis of sexism in the activities of male and female characters, an analysis of sexism in the social and emotional behaviour of male and female characters and an anaysis of sexism inherent in language: that which has to do with choice of vocabulary in the use of grammar and the indirect use of words that clearly indicate a cover- up of sexist language. Mustapha (2012) also grouped and explained the methods for investigating this type of study into two major categories: content analysis and linguistic analysis. Content analysis involves how males are represented in pictures according to their visibility/invisibility which is determined by the number of times the males and females feature in textbooks, the kind of roles represented in the pictures, occupation stereotypes, and relationship stereotypes characterization/depiction of male and female characters (main character representation; experiences in terms of named and unnamed characters. However, Stockdale (2006) employed the use of mechanical method - numbering or counting the number of images and reading their perception or representation, to carry out his studies.

For this study, content analysis is used. This is because according to Mustapha (2012), it indicates the gender that 
is underrepresented or overrepresented, the female and male roles and perpetuation of gender stereotypes in gender roles. The content in this study is categorized into five according to the division of activities ascribed to males and females represented: characterization/depiction of male and female characters, leisure activities, professional/occupational stereotypes, domestic activities, and undesirable qualities of the males and females in the texts. The total number of occurrence of each of the activities as well as their percentages is determined. This is in line with the methods adapted by Opeke (2002) and Mustapha (2012) in similar studies.

\section{Findings/Discussion}

Table 1: Content of English Language Textbooks According to Activities

\begin{tabular}{|c|c|c|c|c|c|c|c|}
\hline JSS/SS & Characterization & Females & $\%$ & Males & $\%$ & Total of $M / F$ & $\%$ \\
\hline Intensive English & & 5 & 6.9 & 67 & 93.1 & 72 & $100 \%$ \\
\hline New Concept English & & 12 & 13.3 & 78 & 86.7 & 90 & $100 \%$ \\
\hline Project English & & 23 & 26.1 & 65 & 73.9 & 88 & $100 \%$ \\
\hline \multirow[t]{2}{*}{ New Oxford English } & & 18 & 25 & 54 & 75 & 72 & $100 \%$ \\
\hline & $\begin{array}{c}\text { Total } \\
\text { Leisure Activities (sports/hobbies) }\end{array}$ & 58 & $18 \%$ & 264 & $81.9 \%$ & 322 & $100 \%$ \\
\hline Intensive English & & 12 & 16 & 63 & 84. & 75 & $100 \%$ \\
\hline New Concept English & & 18 & 25.7 & 52 & 74.3 & 70 & $100 \%$ \\
\hline English Project & & 24 & 23.5 & 78 & 76.5 & 102 & $100 \%$ \\
\hline \multirow[t]{2}{*}{ New Oxford English } & & 31 & 21.1 & 116 & 78.9 & 147 & $100 \%$ \\
\hline & $\begin{array}{c}\text { Total } \\
\text { Professional/ Occupational Stereotypes }\end{array}$ & 85 & $21.6 \%$ & 309 & $78.4 \%$ & 394 & $100 \%$ \\
\hline Intensive English & & 39 & 29.5 & 93 & 70.5 & 132 & $100 \%$ \\
\hline New Concept English & & 56 & 35.7 & 101 & 64.3 & 157 & $100 \%$ \\
\hline English Project & & 48 & 29.4 & 115 & 70.6 & 163 & $100 \%$ \\
\hline \multirow[t]{2}{*}{ New Oxford English } & & 35 & 26.5 & 97 & 73.5 & 132 & $100 \%$ \\
\hline & $\begin{array}{c}\text { Total } \\
\text { Domestic Activities }\end{array}$ & 178 & $30.4 \%$ & 406 & $69.6 \%$ & 584 & $100 \%$ \\
\hline Intensive English & & 86 & 85.1 & 15 & 14.9 & 101 & $100 \%$ \\
\hline New Concept English & & 92 & 81.4 & 21 & 18.6 & 113 & $100 \%$ \\
\hline English Project & & 88 & 82.2 & 19 & 17.8 & 107 & $100 \%$ \\
\hline \multirow[t]{2}{*}{ New Oxford English } & & 90 & 73.8 & 32 & 26.2 & 122 & $100 \%$ \\
\hline & $\begin{array}{c}\text { Total } \\
\text { Undesirable Qualities }\end{array}$ & 356 & $80.4 \%$ & 87 & $19.6 \%$ & 443 & $100 \%$ \\
\hline Intensive English & & 83 & 73.5 & 30 & 26.5 & 113 & $100 \%$ \\
\hline New Concept English & & 92 & 76.7 & 28 & 23.3 & 120 & $100 \%$ \\
\hline English Project & & 79 & 86.8 & 12 & 13.2 & 91 & $100 \%$ \\
\hline \multirow[t]{2}{*}{ New Oxford English } & & 87 & 74.4 & 30 & 25.6 & 117 & $100 \%$ \\
\hline & Total & 341 & $77.3 \%$ & 100 & $22.7 \%$ & 441 & $100 \%$ \\
\hline
\end{tabular}

Based on the study, the following were found:

\subsection{Characterization/Depiction of Male and Female Characters}

In table 1, the males dominated the characterization of all the twenty four texts. For example, in New Oxford Secondary English Course, there are $16 \%$ female main characters in the reading passages while the males are $84 \%$. In Intensive English, the total population of the males is $93.1 \%$ while that of the females is $6.9 \%$. In fact, the gender disparity started from the cover page where there are pictures of three boys being taught by their parents and no girl. The total number of female main characters in all the books used is $18 \%$ while that of the males is $81.9 \%$ indicating a very wide gap of discrimination against the females. In the texts, the males are portrayed as the heroes, strong, daring and adventurousJunior English Project 1 p. 64, 65, 170, Intensive English SS2 p. 154, New Concept English SS2 p. 34.

\subsection{Leisure Activities}

In all the twenty four series of the four books, the leisure activities of the females are shopping, gardening, watching 
films, and few sporting activities - New Concept English JSS1 pages 84 and 85.

In fact, some of the series remained silent in leisure activities of the females but the males are presented as enjoying the following leisure activities: sporting - Intensive English SS2 p. 11, New Oxford Secondary English Course JSS1 p. 105, Junior English Project JSS1 p. 80, 81, New concept English JSS1 p. 23, 25, 52, Junior English project JSS 1 p. 52 - hunting, driving reading, listening to news and playing draft game. The total number of females enjoying leisure activities is $21 \%$ while that of the males are $74.4 \%$. The females are still discriminated against under this heading.

\subsection{Professional/Occupational Stereotypes}

All the series of the books used in this study indicates that only the females are Nurses, secretaries, traders, dressmakers and rarely teachers. The males are projected as daring soldiers, medical doctors, hunters, mostly teachers, police, scientists, managing directors, drivers, lawyers, lectures, leaders (kings) and footballers - New Oxford Secondary English SS3 p. 40, 149, JSS 2 p. 5, SS2 p. 49, Junior English Project JSS 2 p. 170, JSS1 p.18,31,25,27,29,63,175,171,172 p. 170, Intensive English SS2 p. 97, 111, 82, 59, JSS3 p. 59, JSS2 p. 44, 207, SS1 p. 107, New concept English SS2 p.62. Here, the males are ascribed professions considered as challenging ones. The total of females under this heading is $30.4 \%$ while the males have $69.6 \%$.

\subsection{Domestic Activities}

The domestic activities assigned to the females in the twenty four series studied include drawing water, cooking, home keeping child care, serving food, watering gardens among other related activities. The males, on the other hand, are shown to play around and wait for food to be ready. This is an indication that the bulk of the domestic work rests on the females. The females are thus, portrayed as the only ones to keep homes and this shows discrimination. Some examples are recorded in Junior English Project 1 p. 65, 81 New Oxford English JSS3 p. 108, 118, JSS1 p. 2,4, 29, 48, 55, 126, 127, SS3 p. 28, 74, Intensive English SS2 p. 97, 158, JSS3 p. 10, 11, JSS3 p. 42, 59, 68, 69, 142, JSS 2 p. 168, 80 , New Concept SSS2 p. 80, JSS3 p. 65, JSS 2 p. 26, 75. The females record $80.4 \%$ while the males indicate $19.6 \%$.

\subsection{Undesirable Qualities}

In the twenty four series of the books studied both the males and females have both desirable and undesirable qualities but the undesirable qualities of the females are on the high side. The females are presented as old, poor, quarrelsome, lonely not for schooling, cheats, maltreated, dressing indecently and unable to stay in marriage. The males, however, are seen as armed robbers, cheats and playing pranks. The significant thing here is that the females are unveiled more as being petty while most of the desirable qualities are ascribed to the males: the males are seen to be studious, brave, strong, professionals, leaders, daring, etc. Some examples are seen in New Concept SS2 p. 154, JSS3 p. 34, SS1 p. 35, 103, 125, New Oxford English JS2 p. 190, Intensive English SS2 p 111, JSS3 p. 68, 69, Junior English Project JSS2 p. The undesirable qualities of the females are $77.3 \%$ while that of the males are $22.7 \%$.

\subsection{Other Findings}

The general population of males in all the series is higher than that of the females. Most of the example used to explain terms in each of the books mainly favored the males. The stories in the reading passages mostly highlighted the males and they are depicted more than the female characters. Some of the roles assigned to the females also indicate sexism. For example, in New Concept English SSI, p. 103, a girl runs away from home. In SS2 of the same book, p. 154, some young men jeered at a lady who was not even dressed badly "Sister covers your bosoms!" giving the impression that women are known for indecent dressing. In another series of the same New Concept English (SS1 p..35), Dogo drove his first wife from the house because the second wife merely called her a witch. "In her moments of hallucination, she accused the first wife of bewitching her. That was what Dogo was waiting to hear. In a fit of rage, he drove the first wife from the house". The females are presented here as people who are characterized with domestic scuffles and who are always at the mercy of their husbands. Also in the same book (New concept English JSS 3 p.34, one of the sentences reads "Mrs Olisa is not a good wife. She cheats on her husband." This gives the impression that wives are unfaithful to their husbands.

It was also found that there are more images of the males than the females in all the series and most of the 
pictures present a positive representation of the males. For example, in all the books used for the study, there are more images of the boys reading; rarely is such seen in the girls. Some of the examples are seen in New Oxford English JSS 1 P.6, 7, 41, 73, 158, JSS 2 p. 42, 83, 11, 30 and 23. The pictures mainly showcase males reading books indicating that schooling or reading is not necessarily for females.

Equally, where there are stories of the animal kingdom, the use of the pronouns 'he' and 'him' is employed to represent the animals thereby perpetrating gender disparity. Also, in any passage where the gender is not known, the books preferred to use the pronouns 'he' or 'him' to present the questions accompanied with the passage.

On the other hand, the males were presented as thieves and armed robbers in almost all the books used in the study apparently to show that the males also have faults. This aspect is the major indication of bias against the males because females also steal and indulge in robbery. There are also few instances of where the males are presented in bad light but generally, the unfair representation of the females are more and their entire population in the book is lesser than that of the males.

\subsection{Implication to Classroom Pedagogy}

Gender disparity which has eaten deep into the school system, need to be decisively fought by all the stakeholders in the education system. The bulk of the fight rests solely on the classroom teachers who have direct contact with the students in the classrooms and they are equally the ones who apply what is written in the textbooks.

In the classrooms as well as in authorship of books, gender fair terms should be used. This helps to eliminate stereotyping and give the students plain environment to complete effectively with others irrespective of gender.

In addition during classroom instructions, teachers be careful to use gender fair terms. Also, the teacher should take care not to restrict questions asked to students to a particular gender, perhaps because it is believed that a particular gender do better in sciences or arts subjects.

It is sometimes erroneously assumed that males are better leaders. Thus care should be taken not to chose class prefects or student school functionaries based on gender especially in co-education schools where it is seen to be the normal thing to assign the position of senior prefect to males and females made to be assistants.

\section{Conclusion/Recommendations}

This study shows that there is a high level of gender insensitivity and disparity in English language textbooks used by students which would not permit meaningful literacy development. Generally, the worst hit of this discrimination is the females who bear the brunt of degradation, subordination, invisibility and exclusiveness in all the textbooks used.

The effect of gender desparity on students' literacy development could be very disastrous if urgent steps are not taken to curb it. This owes to the fact that when students begin to adopt the sexist stereotypes, they may be prone to inferiority complex and low self esteem which invariably would affect their academic achievements. Moreover, the stereotypes may limit the females or males to educational choices that may rob them of meaningfully contributing to the society in future thereby restricting them to certain professions they would not ordinarily have opted for. The females that have been stereotyped as home makers may begin to think of marriage early enough instead of advancing their educational pursuit and this might impede their literacy acceleration. The society as a result is robbed of the meaningful contributions and positive impacts that would have been made by the males and females in the careers dropped or pursed as a result of the effect of stereotypes.

These problems need to be arrested early enough to enhance the development of literacy in Africa, Nigeria in particular. To achieve this, sexism need to be eradicated from all the students' texts especially the English Language textbooks which serve usually as the child's first introductory encounter to reading and written words. To ensure gender fairness, the students' textbooks should be revised to eliminate every form of discrimination against males and females. There should be guidelines provided for the authors and publishers in the production of books to ensure gender equality in future. Sensitization training as well as workshops should be conducted frequently for classroom teachers and teacher trainers, authors and publishers on gender issues and, gender education courses need to be introduced in both the universities, colleges of education as well as every higher institution in Nigeria. The students themselves also need proper orientation on gender issues and career choices.

The government's involvement in combating the menace of gender discrimination is very vital. New policies and guidelines that would ensure gender equality in the school system (including authorship and production of gender parity textbooks) should be made and its implementation monitored. Commitment to these activities would not only help in the 
achievement of the 2015 Millennium Development Goals of good and quality education for all, but go a long way to enhancing literacy development in Nigeria.

Since it has been found that gender discrimination exists in English language textbooks, it is suggested that further research be carried out in other textbooks like mathematics, science and other school textbooks to see whether gender discrimination is also exhibited by the authors.

\section{References}

Fung, A. and Ma, E. (2006).Formal vs. informal use of television and gender-role stereotyping in Hong Kong.In Sex Roles.

Ifegbesan, A. (2010). Gender- stereotypes, beliefs and practices in the classroom: The Nigerian post- primary school teachers. In Global Journal of Human Science.Vol 10, Issue 4 (ver 10). Ogun: Department of Curriculum Studies and International Technology, Faculty of Education, Olabisi Onabanjo University, Ogun State, Nigeria.

Martin, C. L \& Halverson, C. F (1981). A schematic processing model of sex-typing and stereotyping in Children.In Child development, $52,1119-1134$.

Mustopha, S (2012). Gender equality in and through education in Nigeria: Gender representation in learning materials. Sheffield Hallam University Research Archive. http://shura.shu.ac.uk

Opeke, R (2002). Unequal chances: The case of female pupils and English language textbooks. In Perspectives on Applied Linguistics in Language and Literature. Ibadan: Stirling-Horden Publishers (Nig) Ltd.

Oyebola, O. (2004). Gender approach to writing children's literature: A study of gender balance in sellected genersal reading books for children authored by Nigerians. In Literacy and Reading in Nigeria, Vol 10 (1). Reading Association of Nigeria.

Stockdale, D.A. (2006). Gender representation in an EFL textbook. A paper submitted to the school of Humanities of the University of Birmingham, UK.

UNESCO (1998).Gender Sensitive Module. France: UNESCO. 